\title{
Childlessness and Assisted Reproduction in Europe*
}

\author{
Patrick Präg
}

Department of Sociology and Nuffield College, University of

Oxford, United Kingdom

Tomáš Sobotka

Austrian Academy of Sciences/Vienna Institute of Demography, Austria

Eevi Lappalainen

Anneli Miettinen

Anna Rotkirch

Population Research Institute, Väestöliitto, Finland

Judit Takács

Centre for Social Sciences, Hungarian Academy of Sciences, Hungary

Annalisa Donno

Maria Letizia Tanturri

Department of Statistical Sciences, University of Padova, Italy

Melinda Mills

Department of Sociology and Nuffield College, University of Oxford, United Kingdom

July 2016

\footnotetext{
*This report is deliverable D4.8 of the research project 'Families and Societies: Changing families and sustainable societies. Policy contexts and diversity over the life course and across generations,' summarizing the key findings of its Work Package 4: 'The changing role of children and societal implications. Assisted reproduction, late fertility, and childlessness.' The report was published as Working Paper 69 of 'Families and Societies' in February 2017. The research leading to these results has received funding from the European Union's Seventh Framework Programme (FP7/2007-2013) under grant agreement no. 320116 for Families and Societies,
} 


\begin{abstract}
This deliverable summarizes key findings of Work Package 4, which focused on the areas of childlessness and assisted reproductive technology (ART). We summarize trends, predictors on the macro- and the microlevel as well as narratives pertaining to childlessness. We also synthesize the central findings with respect to ART, showing the prevalence of ART usage across Europe, variation in the regulation of ART, and consequences of the proliferation of ART. These findings provide the strong foundation for policy recommendations, in addition to providing evidence of the impact that this Work Package has already had.
\end{abstract}

\title{
Contents
}

1 Introduction 2

2 Childlessness in Europe 3

2.1 Childlessness trends in Europe . . . . . . . . . . . . . . . . 3

2.2 Macro-level determinants of childlessness . . . . . . . . . . . . . 8

2.3 Micro-level determinants of childlessness . . . . . . . . . . . . . . 9

2.3.1 Common determinants of childlessness across Europe. . . 10

2.4 The changing association between education and childlessness . . 12

2.4 .1 Life trajectories and childlessness . . . . . . . . . . 13

2.4.2 The multidimensional factors behind childlessness . . . . 14

2.4.3 Comparing unconvinced and persistent childlessness . . . 14

2.4.4 Childlessness increase: the relative contribution of changes in structure and propensity . . . . . . . . . . . . . 15

2.5 Narratives of childlessness $\ldots \ldots \ldots$. . . . . . . . . . 15

3 Assisted reproduction in Europe $\quad 19$

3.1 Prevalence of ART in Europe . . . . . . . . . . . . . . . . . . . . 19

3.2 ART regulation in Europe . . . . . . . . . . . . . . . . . . . . 20

3.3 Consequences of assisted reproduction . . . . . . . . . . . . . 22

4 Policy recommendations 22

4.1 Childlessness . . . . . . . . . . . . . . . . . . . . . 22

4.2 Assisted Reproduction . . . . . . . . . . . . . . . . . . . . 24

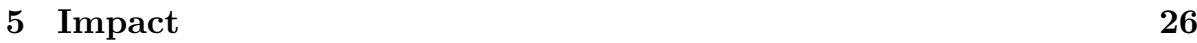

\begin{tabular}{lll}
\hline 6 & Conclusion & 27
\end{tabular}

\section{Introduction}

The objective of Work Package 4 was to examine the rise, determinants, and societal consequences of assisted reproduction, late fertility, and childlessness. In the last decades, European societies have experienced massive changes in the postponement in the age of having a first child, shrinking family sizes, and increased levels of (in)voluntary childlessness (Mills et al., 2011; Rotkirch, 2007; Sobotka, 2010, 2017, Tanturri and Mencarini, 2008). The rise in late fertility has been accompanied by the rapid diffusion of various types of assisted reproductive 
technologies (ART). ART has created new opportunities for many couples and individuals previously considered infertile or those who desire to have children at a later age. This Work Package examined the core aspects of these topics that have been previously neglected, took stock of the current situation, charted trends and made evidence-based recommendations.

The next Section provides an overview of findings pertaining to childlessness in Europe. First, we examine childlessness among women in a quantitative perspective, focusing on trends and relevant determinants and measures. Second, we report key findings with respect to macro-level determinants of childlessness among women. Third, we outline the central micro-level determinants of childlessness among women and men by examining core characteristics of childless individuals such as higher education or marital disruption. Lastly, we report narratives of childlessness as distilled from qualitative interviews.

Following this, in Section 3 we report diverse findings on ART in Europe, discussing which factors have given rise to ART use, the level of ART usage and examine ART regulation in Europe. We then turn to a more detailed examination and review the demographic consequences of ART, psychological and health consequences of ART for parents and children, economic costs and the inequality of access. Based on these results, we generate policy recommendations in Section 4 and outline the impact that the work package has already had in Section 5, followed by brief conclusions. The research presented in this summary report builds on previous deliverables, namely the state-of-the-art literature review (Mills et al. ,2013), reports on the demographic consequences of assisted reproduction (Präg et al., 2015) and its regulation (Mills et al. 2014. Präg and Mills, 2015), as well as the deliverables on the trends and country differences (Miettinen et al. 2015) and narratives of childlessness (Takács and Faludi, 2016).

\section{Childlessness in Europe}

\subsection{Childlessness trends in Europe}

Most of the social, economic, and cultural trends of the last half a century seem to steer women and men away from having children. Reliable contraception, increased acceptance of voluntary childlessness, extended education, the trend in delayed union formation and childbearing, higher levels of family instability, as well as economic uncertainty make starting a family increasingly challenging for many men and women. The expanding research on childlessness also presents considerable ambiguity about preferences about having children among childless people, which often persists into late reproductive ages Abma and Martinez, 2006). While many childless women aged 35-44 state that they intend to have children in the future, reproduction at advanced reproductive ages increases the risk of infertility and involuntary childlessness (Mills et al. 2011). Highly educated women often have to face difficult choices between having children and advancing their career, especially in countries that do not provide sufficient support to parents in the form of widely accessible public childcare, a flexible and well-functioning labor market, or where men do not provide a great deal of help with childrearing and household work.

It is surprisingly difficult to study how childlessness changes over time or 
how it varies across countries. In fact, different data sources often give contradictory accounts of the levels of childlessness. This is attributed to differences in questions asked in censuses and surveys, various assumptions employed when combining vital statistics or assembling register-based data, as well as the selectivity of respondents, non-response, and misreporting in surveys, which can all bias childlessness estimates (Bhrolcháin et al. 2011).

In the current study we present key findings on long-term changes and crosscountry differences in childlessness among women born in 30 European countries between 1900 and 1972. These data are based on multiple sources, especially population censuses (different years, 1961-2011), a long series of vital statistics data that allow reconstructing cohort fertility histories, data from population registers, and, in a few countries (especially France and Germany), large-scale survey data. The selection of data is discussed in more detail in Sobotka (2017). Two databases that were primarily used are: the Human Fertility Database (HFD, 2015) and the Cohort Fertility and Education (CFE, 2015) database. Both databases served as a source of census data; the HFD also provided data on cohort parity distribution generated from population registers and from longterm series of vital statistics data. Due to lower data availability and higher uncertainty about childlessness among men, we focus on childlessness among women only. The available research shows, however, that men remain childless more often than women.

The reconstruction of Europe-wide trends in childlessness among women born since the early 20th century (Figure 1) reveals three major findings. First, in the past, childlessness was high in most parts of the continent, especially among women born in the first two decades of the 20th century (see also Rowland, 2007). Historical levels of childlessness among women born in 1900-1915 were higher in most European countries than the childlessness levels among women born around 1970, who are now reaching the end of their reproductive career. In all countries with available data except Slovakia, the early 20th century cohorts had levels of childlessness of around 20 per cent or higher.

Second, most countries have experienced a U-shaped trend in childlessness among women born during the 20th century. Women born in the 1940's experienced the lowest childlessness levels, with one in ten remaining childless. These were the late 'baby boom' cohorts in Western countries who also had generally higher fertility rates and low rates of non-marriage. Third, childlessness levels and trends differed widely between the East and the West of Europe, with Central and Eastern Europe (CEE) reaching particularly low and stable levels of childlessness, averaging 7-8 per cent among women born 1940-65. These women lived their prime reproductive years during the era of state socialism in this part of the continent, when marriage and reproduction took place relatively early and voluntary childlessness was rare. The East-West contrasts in childlessness, however, clearly precede the post-war political division of Europe, as the CEE countries had on average lower levels of childlessness already among the women born in the 1900's to the 1930's.

Figure 1 also sheds light on recent contrasts in childlessness trends in broader European regions. In CEE, childlessness started increasing among women born in the 1960's, although from a low level, reflecting a shift towards lower and later fertility after the political regime change in 1989-1990. A rapid rise in childlessness has also recently emerged in Italy and Spain. This trend suggests that Southern European countries are becoming the 'hotspots' of childlessness 


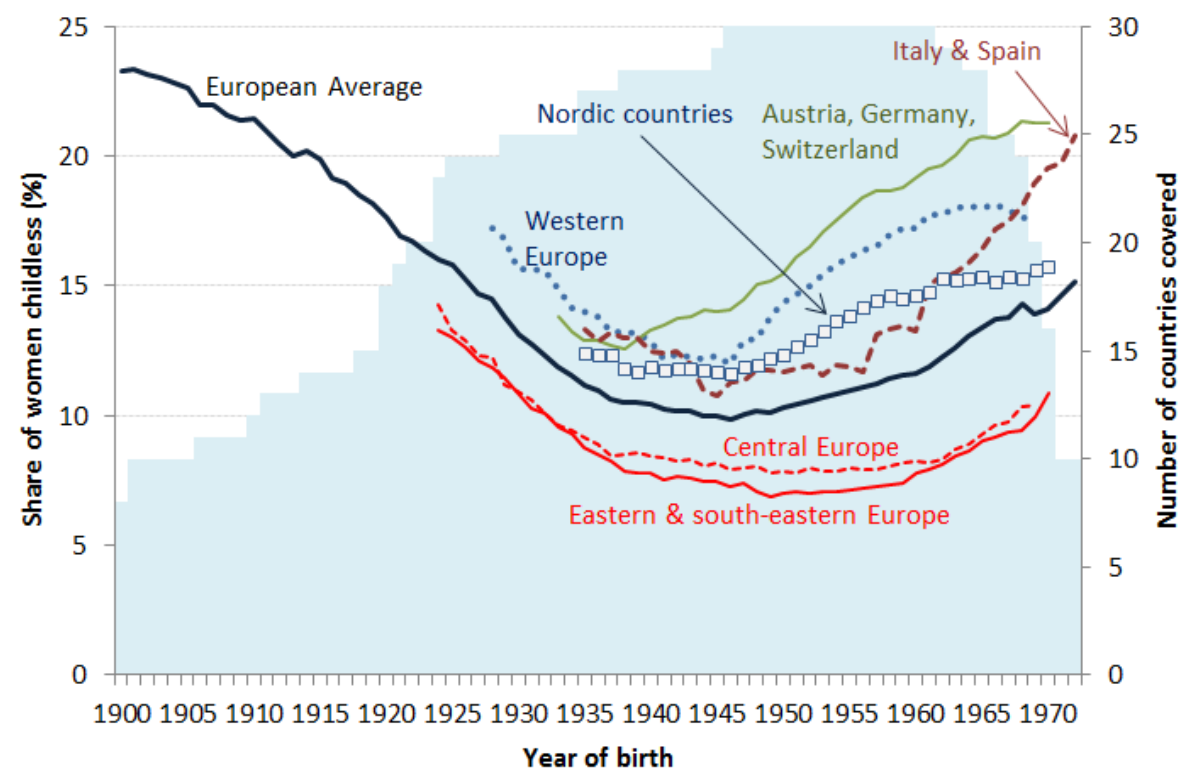

Figure 1: Average childlessness levels in Europe and in broader European regions; women born in 1900-1972 (simple average based on data for all available countries)

Note: See Sobotka (2017) for definition of regions and for data sources.

in Europe. Childlessness also reached high levels in the three predominantly German-speaking countries, where around one out of five women remains childless, but, in contrast to Southern Europe, the long-term rise in childlessness in this region appears to be coming to an end among women born after 1970. In addition, childlessness appears to have peaked in Western Europe at 18 per cent and has been only marginally rising in the Nordic countries, where it averaged 15 per cent in the late 1960's cohorts (but close to 20 per cent in Finland). Among the youngest cohorts analyzed, childlessness in CEE is still far below the European average, with only 8 per cent of women from Bulgaria, the Czech Republic, and Russia born in 1968 remaining permanently childless in comparison to the European-wide average of 14 per cent (Figure 2). In contrast, Germany and Switzerland have a striking level of high childlessness level of over 20 per cent. Even in Germany, the geopolitical East-West division of Europe before 1990 still shows up: Eastern German women born in 1968 have considerably lower levels of childlessness (16 per cent) than their Western German counterparts (24 per cent). The evidence also shows widening cross-country differences in childlessness levels among the women born in the 1950's and 1960's (data not shown here).

Is childlessness in Europe closely tied to the completed fertility rate? Although it could be expected that high levels of childlessness partly account for low fertility in many European countries, Figure 3 suggests there is no consistent relationship between them. Some European countries, such as Ireland, United Kingdom and Finland, combine relatively high levels of childlessness (18 per cent or higher) with higher levels of cohort fertility (above 1.8 children per woman). 


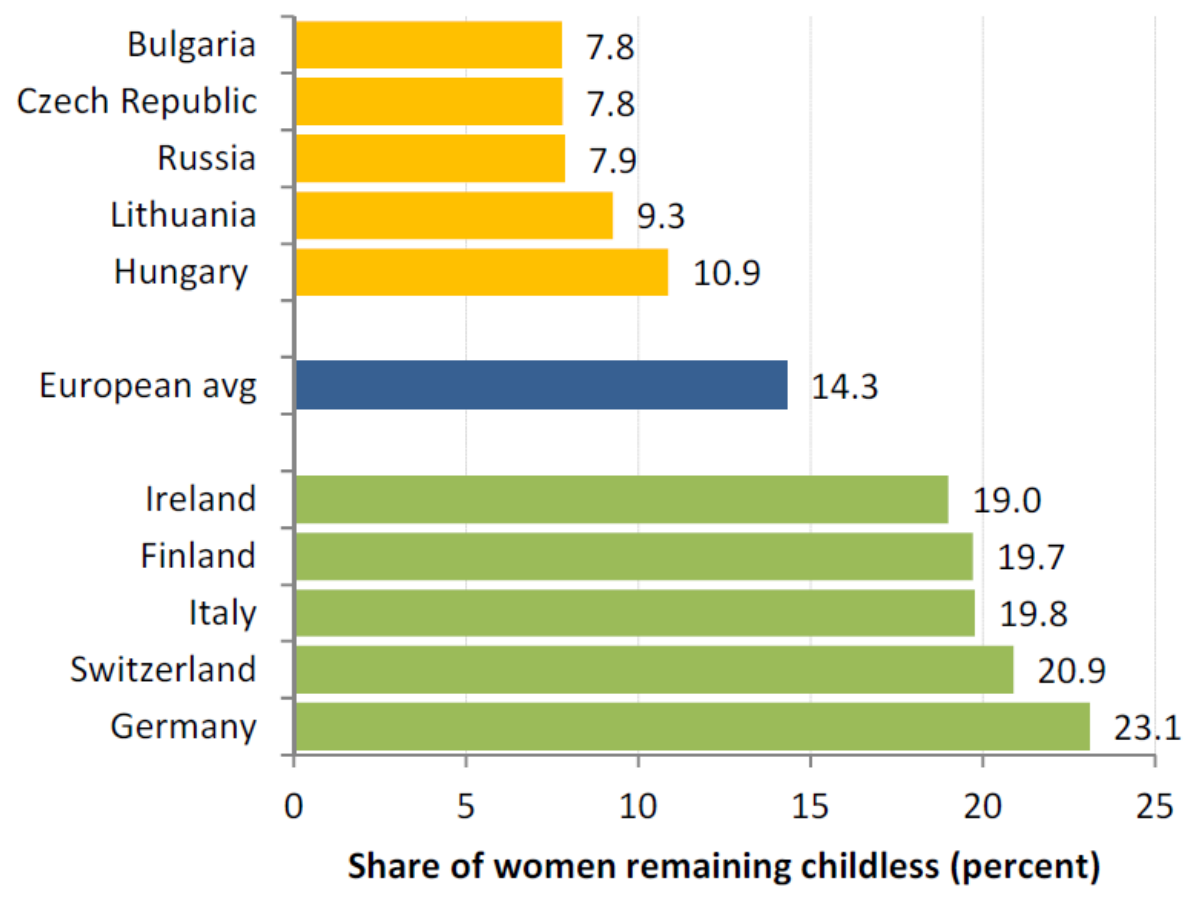

Figure 2: Ranking of European countries by childlessness level among women born in 1968: five highest-childlessness and lowest-childlessness countries Note: See Sobotka (2017) for definition of regions and for data sources. 


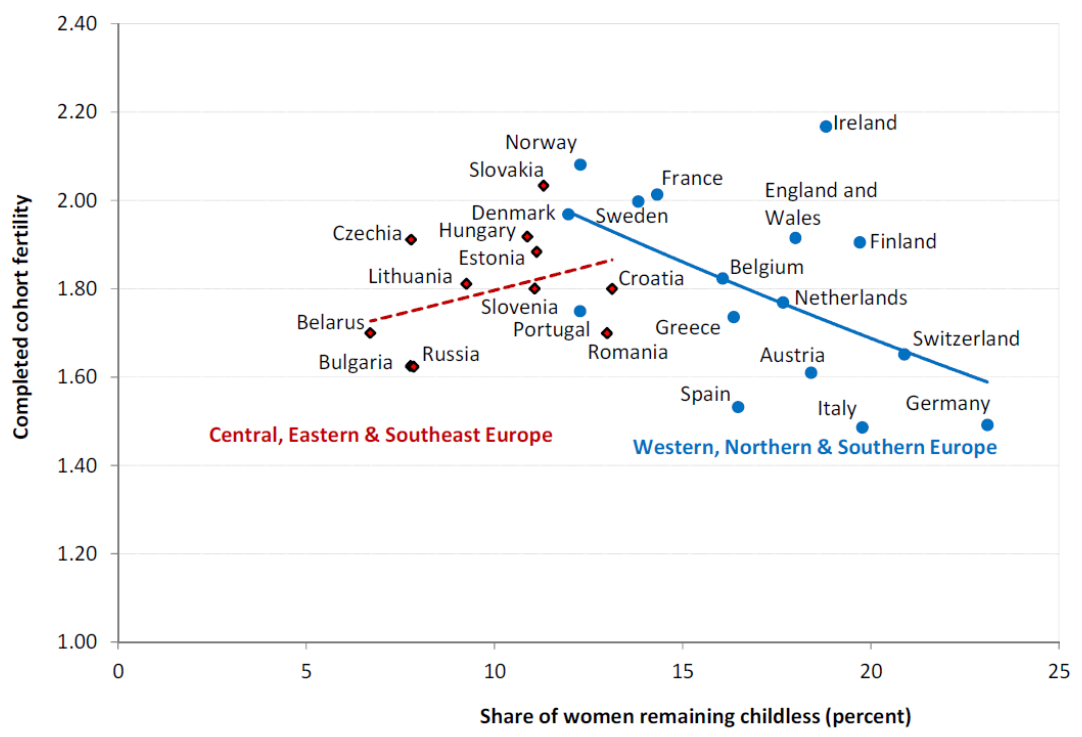

Figure 3: Completed fertility and permanent childlessness (in per cent) in European countries; women born in 1968

Note: See Sobotka (2017) for definition of regions and for data sources.

In contrast, some CEE countries, especially Bulgaria and Russia, combine low completed fertility (around 1.6 children per woman) with low levels of childlessness (around 8 per cent). Looking separately at CEE and other parts of Europe gives a more consistent picture for Western, Southern and Northern Europe, where higher childlessness goes hand in hand with lower fertility (but the correlation is not very strong), whereas a surprisingly opposite pattern (again, with a relatively weak correlation) emerges in the CEE countries.

Current levels of childlessness have a different character than the historical levels of childlessness observed among women born in the early 20th century, where in the case of the latter; childlessness was closely linked to non-marriage. For the women born around 1970, childlessness is more varied, related to a host of factors including voluntary childlessness, and is less connected to nonmarriage. While childlessness has been stabilizing in Western and Northern Europe, it is likely to continue to rise considerably in Southern Europe, where up to one quarter of women born in Greece, Italy and Spain that were born in the 1970's may remain childless. Childlessness is also likely to rapidly increase in CEE countries, where a new pattern of delayed reproduction has been taking hold since the 1990's. As a result, this region will experience an erosion of its distinct low levels of childlessness pattern. At the same time, the rise in childlessness in CEE may be slowed down by the continued negative perception of voluntary childlessness across much of the region (Merz and Liefbroer, 2012).

Comparable data on male lifetime childlessness remain scarce. With the exception of the Nordic countries and France, data on male childlessness are currently drawn from population surveys with relatively small samples, making the estimations less reliable. In addition, time trends in male childlessness 
are, in general, not available. As was the case for women, male childlessness shows considerable variation between countries. Male lifetime childlessness is the highest (above 23 per cent among men aged 45-49) in Finland, Italy, Germany, the UK, and the Czech Republic, while Estonia, Russia, and Georgia have only one in ten childless men. Due to these data limitations, we were unable to study all macro-level determinants of childlessness among men.

\subsection{Macro-level determinants of childlessness}

Once fertility has fallen to around or below replacement level, countries with similar levels of completed fertility may have quite different proportions of childless women. High levels of childlessness at or above 20 per cent are found in both relatively high and low fertility countries: in Austria, with a total fertility rate (TFR) in 2012 at 1.44, versus England and Wales with a TFR of 1.94. Respectively, countries with low levels of childlessness (at or below 10 per cent) exhibit both high TFR (France with a TFR above 2) and low TFR (Czech Republic with TFR 1.45 in 2013). We therefore explored how various demographic and social indicators affect how childlessness is distributed among different subgroups of the population in Europe.

Differences in childlessness are not easily or directly mapped in a straightforward manner to the overall fertility born to women in Europe. Among women born in the early 1940's in different European countries, there was no clear relationship between the average number of children they had during their lifetime and the proportion who did not become mothers. Some countries had slightly positive association, but others showed a negative one. Only Ireland is a clear exception in this respect, since the country has displayed high fertility as well as high levels of female childlessness throughout the last century. A weak but statistically significant negative association between completed cohort fertility and childlessness, however, was detected among women born in the 1950's, who experienced the advent of the so-called Second Demographic Transition. In more recent birth cohorts, consisting of women born in the 1960's, the negative association between completed cohort fertility and childlessness has grown even stronger. This suggests that childlessness is an increasingly important component of low fertility in several European countries today.

In spite of marriage losing ground as an obligatory social institution across Europe, the proportions ever married in a population are negatively associated with lifetime female childlessness among women born after the 1950's. Childlessness is also higher in countries where the average mean age at marriage is high and entry into motherhood is delayed. It appears as if obstacles in the transition to adulthood may transform a delay in parenthood into definitive childlessness (Mills and Blossfeld, 2005).

Lifetime childlessness is often associated with levels of education, but also varies strongly with both gender and age cohort. Overall, childlessness is more common among men with limited education, and among women with either very high or very low education. However, the prevalence of childlessness was not associated with women's social position. We found no association between the proportions of women with high education or women's employment rates and female childlessness at a country level. Neither are country-level divorce rates associated with childlessness.

On the other hand, values related to so-called post-materialist values and 
family norms are positively associated with childlessness on country level. Postmaterialist values are measured as respondents to order and authority, but are not directly related to family life or childbearing. In other words, countries with high levels of individualization exhibit higher rates of childlessness.

Overall, most of the increase in childlessness seems unwanted. Intentional childlessness and particularly voluntary childlessness remains rare throughout Europe. There are nevertheless clear country differences: rates of intended and voluntary childlessness are somewhat higher among men than among women, and in the German-speaking countries and the Netherlands compared to other European countries.

We conclude that childlessness in contemporary Europe should no longer be associated with the stereotypical image of a highly-educated and career-oriented woman. Nor is childlessness in any clear way associated with higher gender equity or the proportion of women in the labor market, as is often assumed. The very low rates of voluntary or intended childlessness, combined with the absence of an increase in voluntary childlessness over the last decades, suggests that childlessness in young adults in their late 30's or early 40's is to a large extend involuntary or unwanted. Educational differences in childlessness rates further indicate that unwanted childlessness may now be concentrated among those who lack socioeconomic resources.

\subsection{Micro-level determinants of childlessness}

Numerous studies have highlighted the individual determinants of childlessness among women: socio-demographic (age, sex, union status) and socioeconomic (educational attainment, occupational status) characteristics, values and cultural attitudes (religious practice, attitudes and opinions about gender roles in family life, importance of professional life and family involvement) or early socialization processes in childhood (socioeconomic status of parents, geographical origin, size of the siblings) (González and Jurado-Guerrero, 2006, Hakim, 2003. Hoem et al. 2006; Miettinen, 2010; Portanti and Whitworth, 2009; Szalma and Takács, 2015: Tanturri and Mencarini, 2008).

The traditional explanation of the diffusion of childlessness is often related to the massive increase in women's education and their increased participation into the labor market (Mills et al., 2011). The delay in family formation linked to these processes is often seen as a further cause of involuntary childlessness. At the same time, the rise of cohabitation and couple instability are similarly considered to fuel the process. Research however suggests that the factors influencing childlessness usually differ from those affecting low fertility as a whole and in many cases are found to be context-dependent.

A systematic study across European countries on micro-level determinants of childlessness was lacking. In particular, it was unclear how the phenomenon was spreading across social classes, how it was linked to changes in educational attainment, to the process of union formation and dissolution, as well as the shrinking of sibship size. Moreover, the factors behind men's childlessness are largely unexplored across European countries. Our study is a significant contribution to the literature since it sheds light on many of these issues. 
Table 1: Results of logistic regression analysis for characteristics explaining micro-level childlessness. Reference category fathers and mothers.

\begin{tabular}{|c|c|c|c|c|c|}
\hline Variables & & $\begin{array}{c}\text { Men } \\
30-39 \\
\text { Odds Ratio }\end{array}$ & $\begin{array}{c}\text { Women } \\
30-39 \\
\text { Odds Ratio }\end{array}$ & $\begin{array}{c}\text { Men } \\
40-49 \\
\text { Odds Ratio }\end{array}$ & $\begin{array}{c}\text { Women } \\
40-49 \\
\text { Odds Ratio }\end{array}$ \\
\hline Intercept & & $0.41^{* *}$ & $0.24^{* *}$ & $0.24^{* *}$ & $0.15^{* *}$ \\
\hline \multirow[t]{3}{*}{ Union status (Ref. Married) } & Never married not in couple & $152.56^{* *}$ & $58.98^{* *}$ & $198.83^{* *}$ & $52.80^{* *}$ \\
\hline & Divorced separated & $2.61^{* *}$ & $2.57 * *$ & $3.16^{* *}$ & $2.09^{* *}$ \\
\hline & Never married in couple & $5.67^{* *}$ & $8.71^{* *}$ & $5.46^{* *}$ & $8.02 * *$ \\
\hline \multirow[t]{2}{*}{ Education (Ref. Medium) } & Low & $0.74^{* *}$ & $0.54^{* *}$ & 0.93 & 0.81 \\
\hline & High & 1.17 & $1.67^{* *}$ & $1.45^{* *}$ & $1.47^{* *}$ \\
\hline Health (Ref. No) & Chronic disease & 0.91 & $1.36^{* *}$ & 1.19 & 1.04 \\
\hline Siblings (Ref. No) & Yes & $0.76^{* *}$ & $0.73^{* *}$ & $0.52 * *$ & $0.56^{* *}$ \\
\hline \multirow{5}{*}{ Country (Ref. Italy) } & Finland & $0.26^{* *}$ & $0.45^{* *}$ & 0.64 & 1.33 \\
\hline & Switzerland & 1.15 & 0.79 & $0.67^{* *}$ & 0.86 \\
\hline & Bulgaria & $0.18^{* *}$ & $0.10^{* *}$ & $0.20^{* *}$ & $0.24^{* *}$ \\
\hline & Hungaria & $0.35^{* *}$ & $0.27^{* *}$ & $0.23^{* *}$ & $0.11^{* *}$ \\
\hline & Romania & $0.33^{* *}$ & $0.35^{* *}$ & $0.41^{* *}$ & $0.26^{* *}$ \\
\hline \multirow{10}{*}{ Education*Country (Ref. Medium-Italy) } & Low * FI & 0.96 & 3.16 & 1.94 & $0.41^{*}$ \\
\hline & Low $* \mathrm{CH}$ & 0.79 & 1.02 & 1.16 & 0.94 \\
\hline & Low $*$ BG & $0.46^{* *}$ & 1.2 & $0.34^{* *}$ & $0.32^{* *}$ \\
\hline & Low $* \mathrm{HU}$ & 0.7 & 0.78 & 0.91 & 0.71 \\
\hline & Low $*$ RO & 0.7 & 0.69 & 0.92 & 1.1 \\
\hline & High $*$ FI & 1.46 & $1.60^{*}$ & 1.03 & 0.64 \\
\hline & High $* \mathrm{CH}$ & 0.77 & 1.1 & 1.21 & 1.1 \\
\hline & High * BG & $1.89^{* *}$ & $1.78^{* *}$ & 0.58 & 0.81 \\
\hline & High $* \mathrm{HU}$ & 1.27 & 1.26 & 0.57 & 0.94 \\
\hline & $\mathrm{High} * \mathrm{RO}$ & $1.76^{* *}$ & $1.65^{*}$ & 1.21 & 1.82 \\
\hline
\end{tabular}

\subsubsection{Common determinants of childlessness across Europe}

A first study analyzed micro-level determinants of childlessness in a plurality of European countries (Bulgaria, Finland, Hungary, Italy, Romania and Switzerland), characterized by diverse socioeconomic and value backgrounds, different welfare regimes and dissimilar prevalence levels of childlessness. We focused on the determinants of both temporary (at age 30-39) and permanent (at age 4049) childlessness among men and women. The hypothesis-based on previous findings in literature - that different determinants explain men and women's childlessness was not corroborated by our analysis: the main variables were found to act in the same direction. The results are shown in Table 1 and Figure 4 .

At the same time, the results of the analyses conducted among the childless in their thirties and the forties were not radically different. The magnitude of some relationships differed, but in general the determinants of postponement in earlier ages were similar to the factors behind childlessness in later stages of life. This means that those who postponed fertility were similar to those who were more likely to remain childlessness at the end of their reproductive life. The comparison between Eastern and Western European countries in this respect reveals that the anticipated process of family formation can be one of the major factors behind low levels of childlessness registered in Eastern Europe.

Pooled and harmonized data from different data sources demonstrated that there are important commonalities among countries: couple status is the most important variable influencing both permanent and temporary childlessness virtually everywhere. Its impact is similar between genders, but stronger in magnitude among men. Childbearing has thus remained a couple project until now, and in most case is still linked to traditional marriage. The likelihood of remaining childless is substantially higher among those who never entered a couple union, but considerably higher also among those who experienced cohab- 


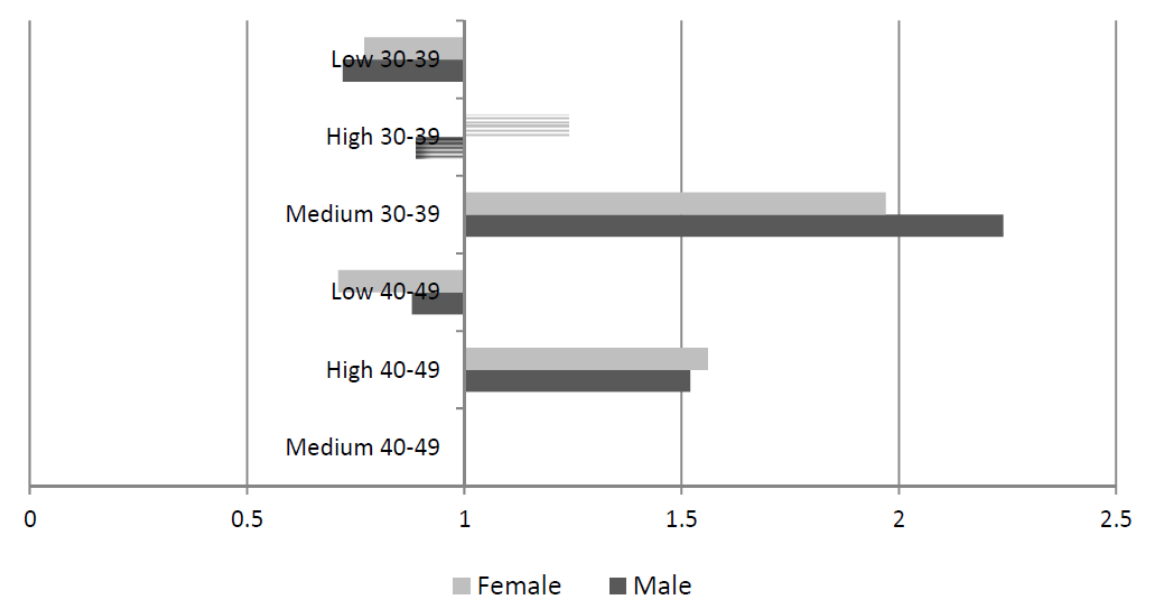

Figure 4: Odds ratios of being childless for the interaction between age and education level by gender

Note: Dotted bars identify not significant odds ratios

itation or couple dissolution (either divorced or separated). This association is observed everywhere, but the effects are larger in magnitude in Eastern European countries, where traditional marriage is more widespread and those who are unmarried remain a selective group. As cohabitation spreads, according to the second demographic transition framework (Lesthaeghe, 2014), it is possible that the impact of cohabitation on childlessness becomes more and more similar to that observed for the ever married. Otherwise, childlessness levels could increase even more.

The increase of women's educational attainment and growing female labor force participation have been considered by previous literature as two major factors behind childlessness and in general linked to fertility decreases. The expansion of women's education has been accompanied by a process of a rapid postponement of motherhood and by a notable increase in levels of childlessness. Generally, a positive educational gradient in childlessness has been observed, with highly educated women showing higher childlessness levels in comparison to their medium and lower-educated counterparts, but in some European countries (i.e. Finland) a reversal in the educational gradient has been registered among the youngest birth cohorts, with highly educated women showing a lower risk to be childless than the lowest educated ones.

Our studies confirm that education is an important determinant of childlessness, but that the association is not as strong in terms of magnitude among women and even not significant among Western European men. Less educated individuals have a lower risk of being childless in comparison to medium and highly educated individuals. This is likely attributed to the fact that they postpone less, as they are usually more likely to start the family formation process at younger ages, thus increasing the likelihood to have children also when they are younger. At the same time, individuals with higher education are more likely to be childless in their forties than the lower educated. Highly educated 
individuals tend to delay the decision to have children to pursue a career or to achieve a higher socio-economic status. However, if postponement is extreme (after 40's), it limits the possibility to conceive, especially among women. The most educated thus are more likely to transform a voluntary postponement into "involuntary" childlessness. The growing demand for assisted reproduction all over Europe is evidence of the existence of this mechanism (see Section 3). It is also possible, however, that habits create habits: being used to living without children makes people less prone to change their lifestyles and produces a selfreinforcing mechanism. The most educated decide not to have children in order to avoid both the opportunity and direct costs of parenthood, which may mean that they either initially had different preferences regards childbearing, which are in turn reinforced and allow them to follow a 'childfree lifestyle' (Hakim, 2003). Differently from our starting hypotheses and previous findings (Parr. 2010, Tanturri, 2010), the link between education level and childlessness acts in the same way (in terms of relationships signs) among men and women, but not surprisingly in terms of magnitude, the effect is stronger for women.

Family of origin characteristics also mattered. Only-children are more likely to be childless than individuals with siblings, confirming previous findings. These results pose some concerns for the future. If this mechanism persists, it is possible to envisage a further increase of childlessness when young people coming from smaller families on average than the previous generations enter into their reproductive ages.

Having chronic diseases also increase the risk of being childless significantly only for women, but only at age 30-39 years and only in Western Europe. Women likely prefer pregnancy and deliveries when they are healthy or it may be that chronic diseases inhibit conception or inclination to have a child. It is interesting that the effect disappears at older age. Probably close to the end of reproductive life, women willing to have children accept to enter motherhood even with a chronic disease. For men, the effect is not statistically significant, as they are likely less concerned about physical impediments of entering fatherhood.

\subsection{The changing association between education and child- lessness}

A special focus of our research was devoted to study the link between education and childlessness, which is controversial in recent demographic literature. Generally, a positive educational gradient in childlessness has been observed, with highly educated women showing higher levels of childlessness compared to the medium and lower-educated ones. In some European countries - where the entry of women in tertiary education has a long tradition and the context is characterized by active family-friendly policies (e.g. the Nordic Countries) - a reversal in the educational gradient was registered among the youngest birth cohorts.

Part of our research was therefore dedicated to compare Finland and Italy, two unique case studies characterized by very different institutional contexts, but both showing striking levels of childlessness (over 20 per cent for the cohorts born in the late 1960's, early 1970's). The similar childlessness prevalence observed for the most recent cohort hides interesting differences in terms of childlessness prevalence by education level: Italy shows a persistent positive ed- 
ucational gradient over birth cohort, while in Finland it has reversed, turning out to be negative, among the most recent birth cohorts.

We argue that selectivity processes must be considered when modeling the relation between childlessness and education: decisions affecting the process of childbearing can potentially affect the process of union formation. The hypothesis that education can affect childlessness, both directly, and indirectly, through its link with union formation was verified once we considered union formation and childbearing as jointly determined. Finnish low-educated women had a significantly lower probability ( -18 per cent) to form a union, compared to the most educated ones, while women with a medium educational level did not significantly differ from the reference group. In Italy, both medium and lower educated women had a higher probability to be in union compared to the highly educated ones.

This opposite effect was likely attributed to the different phase these countries occupy in the path toward the gender revolution. In Finland, the rapid expansion of tertiary level of education among women in the younger cohorts has made the lowest educated women a very selective group. This is due to the fact that they are probably less desirable in the marriage market, because of the change in the assortative mating rules that make it more difficult for low (and no more the highly) educated women to enter a union. Conversely, in Italy where highly educated women are still an isolate group, they are less likely to find a suitable partner and enter a union, as women generally marry upward, gender roles are shaped in a traditional way, and highly educated women are more likely to experiencing high opportunity costs in family formation (e.g. they can be discriminated in the labor market).

\subsubsection{Life trajectories and childlessness}

In addition to educational gradients, another interesting focus was on life trajectories (an intersection between union, education and work histories) which was linked to childlessness among French and Italian women in their forties. The comparison between Italy and France represents a sort of paradox, since in France the process of female emancipation was much more noticeable than in Italy, while the prevalence of childlessness in the two countries diverged, but in a counter-intuitive sense. The prevalence indeed was almost the same until the cohorts born in the early fifties (around 10 per cent), but after this time in Italy it increased steeply up to 18 per cent for the cohort born in 1965 and it continued to increase. Conversely, in France it remained almost stable at around 13 per cent. We found that childlessness rather than the result of a single characteristic can be seen as a continuously conditioned process throughout life influenced by many sequences of events. The analysis of past experiences and different events that Italian and French women experienced in terms of employment trajectories and union histories may contribute to explain these differences in the diffusion of childlessness.

We performed a sequence analysis using the optimal matching algorithm. In other words, we grouped the sequences into clusters, taking into account the level of similarity/dissimilarity between the sequences. We identified four typologies of biographies among French women and five for Italians. Childlessness prevalence varied remarkably across clusters, but was not negligible in each cluster. We studied how each cluster may become more or less strongly linked 
to childlessness across cohorts, but also more and more common among women belonging to different cohorts.

Finally, we used these clusters as independent variables in a logit model, in order to estimate the likelihood of being childlessness. We found that virtually all of the clusters are significantly associated with childlessness, regardless the country of residence, and are more predictive than single variables as union status and education. We can conclude thus that childlessness is more frequently the result of a combination of events in the life course rather than associated with one single characteristic or life trajectory. In addition, these paths can differ by country and by birth cohorts.

\subsubsection{The multidimensional factors behind childlessness}

In this line of reasoning, we tried to focus on the combination of factors that can influence permanent childlessness directly or indirectly, in a case study on Italy, using structural equation models. We found that the likelihood of being childlessness was determined by a series of direct and indirect links with other latent variables, representing different features of the individual's life. Specifically, we concluded that primary socialization experiences (measured through two latent variables: the family of origin socio-economic status and the family of origin reproductive history) shaped women's future preferences and choices. They were found to both directly and indirectly affect the women's socio-economic status (measured by education and professional position), which, in turn, influenced childlessness directly and also indirectly, through the link with women's propensity to enter (and remain in) a couple. Results also showed that some latent variables - in particular the socioeconomic status - have diverse weights and different significance paths over birth cohorts. This is most likely attributed to macro-level events that transform labor market rules and due to features changing over time.

\subsubsection{Comparing unconvinced and persistent childlessness}

In our research, we also compared those childless intending to have children in the future (unconvinced childless), those who conversely wanted to remain childless (persistent childless), and fathers or mothers, in order to understand the factors that are associated with an intention to move from childlessness to parenthood, in five European Countries (Italy, Switzerland, Finland, Bulgaria, Romania, and Hungary).

Not surprisingly, the proportion of childless individuals willing to have children was higher among the youngest (aged 30-39) (no less than 14 per cent for men and no less than ten per cent for women), irrespective of sex, but shrunk remarkably in the oldest group (no more than seven per cent for women and no more than twelve per cent for men) (Figure 5 and 6). The unconvinced childless category was always more represented among men. The Swiss and the Italians childless in their Forties - regardless of gender - seemed to be the most eager to enter parenthood than those living in other countries. Therefore it is possible that in Switzerland and Italy the high level of childlessness at 30-39 is just a part of a strategy of postponement rather than a permanent choice to remain childfree forever. It is interesting to note that in these two countries also at age 40-49 the proportions of unconvinced childless was relatively higher compared 
to the other countries, for both men and women. It is plausible that some of the 40-49-year-old childless that declared that they would plan to have children in the future could be depicted as 'permanent postponers.'

Those who persisted with the idea of remaining childless were only slightly more frequent among the oldest group, but the differences were negligible. This result suggests that there is a group of people - small but not insignificant- that since the age of 30 seems to opt for a childfree life, excluding the possibility to have children in the future. An interesting case in this respect is represented by Finland where persistent childless men and women are even more frequent among the youngest group. Finland is outstanding also for the high frequency of persistence in the decision to remain childlessness among women (close to 30 per cent). This is the only country where the proportion of persistent childless women are higher than those of men (around 20 per cent), while in all the other countries women seem less eager to have a childfree life. Persistent childless are rather small in the three Eastern countries, while Italy and Switzerland are in between.

\subsubsection{Childlessness increase: the relative contribution of changes in structure and propensity}

We also calculated how much of the variation in childlessness prevalence across cohorts was explained by changes in the population structure (e.g. more single, more educated), or rather by modification of propensity in the population (for instance, a change in reproductive preferences, regardless the education level). A Fairlie's decomposition technique has been used to disentangle between propensity and structural effects using IPUMS data from Austria, Hungary, Spain and Greece.

Childlessness levels remained constant among women born in 1930's and in 1940's in Austria and in Hungary due to structural changes (e.g. an increase of more educated women, an increase of permanent celibacy) and was compensated by a higher pronatalist attitude. For women born between 1941 and 1945, Austria shows higher childlessness prevalence than any other countries, but differences are principally due to a varied population structure especially in terms of marital status - rather than to a change in the propensity.

In contrast, for women born between 1951 and 1955, the propensity has become an additional factor fueling Austrian higher childlessness levels and explaining cross-country variations. It is interesting to highlight that Austria has evolved into the country with the highest propensity of being childlessness at age 50. Indeed, considering only the structures, gaps between countries would have been smaller than the observed ones. It is striking to note that for this cohort the change in educational structure for the first time contributed to reduce cross-country gaps, rather to increase it, as for the oldest cohorts. It seems that a saturation point had been reached in this respect. Conversely, differences in marital status remained important in explaining cross-country variations.

\subsection{Narratives of childlessness}

In Central-Eastern Europe, there have been only a limited number of empirical studies focusing on childlessness. Another study in this work package con- 

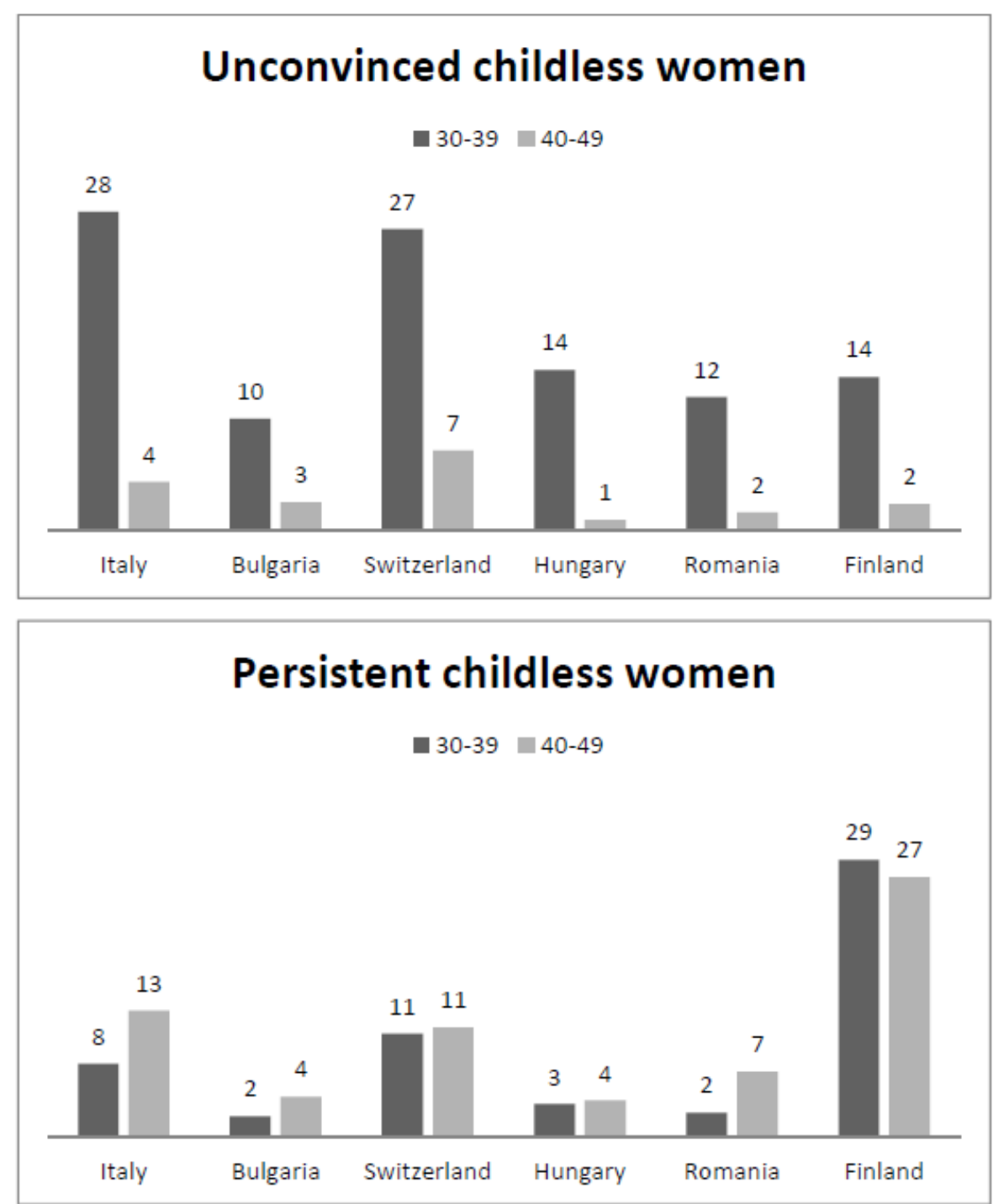

Figure 5: Proportion of unconvinced (childless women willing to have children in the future) and persistent childless women (childless women who do not want to have children in the future) in the sample by age group and country of residence. 

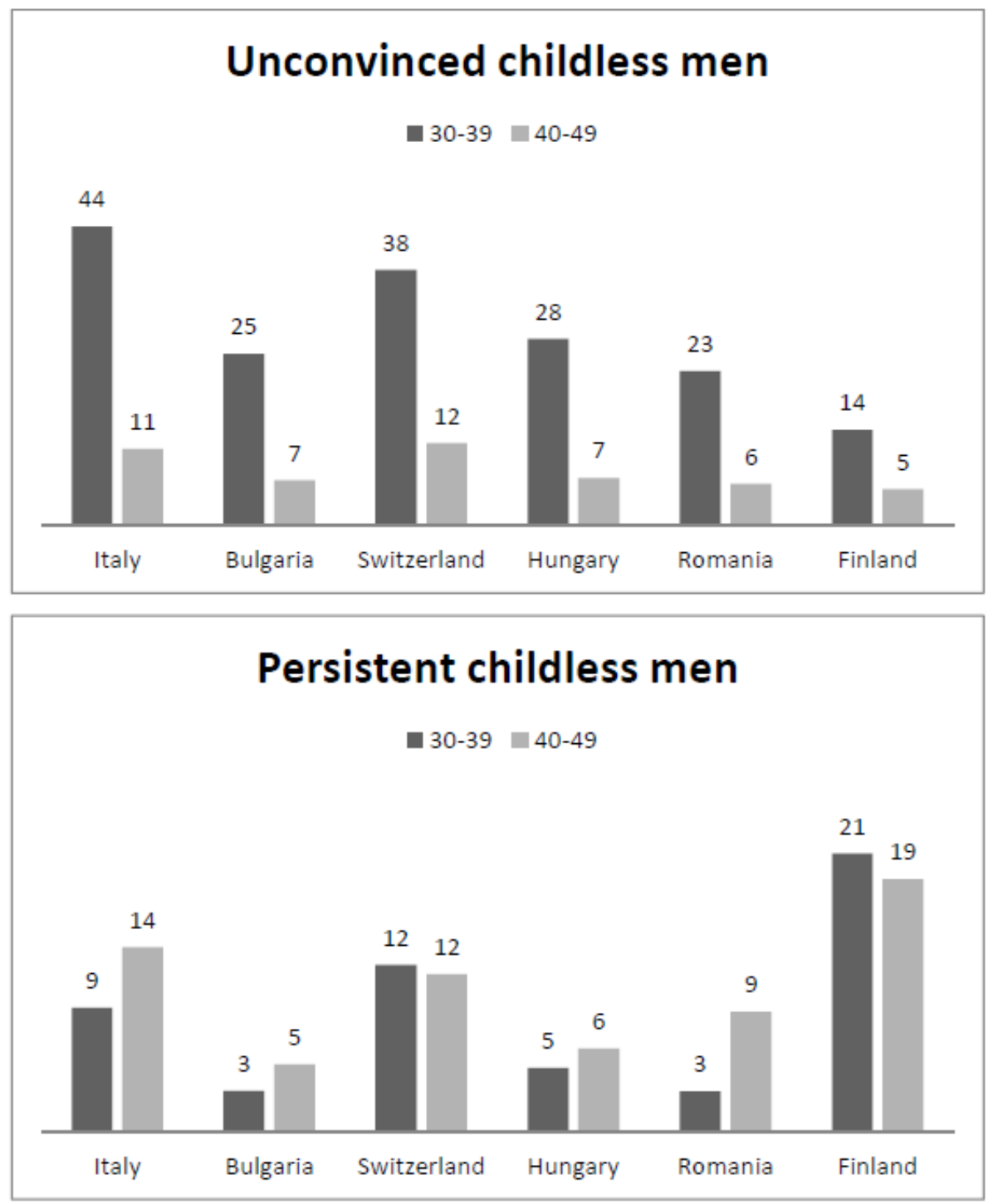

Figure 6: Proportion of unconvinced (childless men willing to have children in the future) and persistent childless men (childless women who do not want to have children in the future) in the sample by age group and country of residence 
tributed to the exploration of the factors and processes that characterize the social phenomenon of childlessness in present-day Hungary and Romania. The main research questions included whether any patterns of (intentional) childlessness could be identified according to basic demographic traits and other important personal characteristics. The empirical base of our study included 25 expert interviews and a set of 106 semi-structured in-depth individual interviews conducted with childless Romanian and Hungarian women at the end (or very close to the end) of their reproductive career.

Our qualitative findings complement previous quantitative findings (Szalma and Takács, 2015) in several ways. Regarding the age effect, it can be stated that with the postponement of age at first birth, most adults in contemporary Europe are nowadays childless for at least one decade. Lifetime childlessness or permanent childlessness means that an individual has not had children by the end of their reproductive life, which for women is around 45 years and for men has no clear upper limit. However, today few European men or women become parents after turning 40. There are not only biological differences that exist between men and women regarding the timing of childbearing but there are also culturally constructed and institutionalized differences. Society views men and women differently in this regard when it comes to age. According to Fasouliotis and Schenker (1999) and Schenker (2005), this can be explained by their different commitment to parenthood as in most societies it is still women who do the bulk of childrearing. Moreover, this gendered bias is also institutionalized: In most countries - including Hungary and Romania-, there are strict age limits for participating in ART for women but not for men. Our findings complemented previous quantitative findings regarding the age effect especially by highlighting the culturally constructed and institutionalized age norms of becoming mothers in the two societies.

Regarding social status, including the effect of education, employment and financial resources, previous findings showed that education had different effects on men and women: higher education of men was usually related to lower levels of childlessness, while the opposite was true for women. In our samples many highly educated women postponed having children and remained childless: they spent more time in education and entered the labor market later, while a stable labor market position seemed to be an important precondition for becoming a parent (especially in these two post-socialist societies). It is also a common expectation that a higher level of education is less of a negatively determining factor for men than it is for women-although men with higher qualifications can also delay becoming parents if they start their careers in the labor market later, but in their case there is no strict biologically determined age limit to becoming a parent, so they can have a greater chance to become fathers at a later stage in life as well. Our interviewees reflected on the fact that combining parenthood and paid employment can be more difficult for women than for men: thus employment can have a negative relationship with entering parenthood for women, and a positive one for men. In addition, not having sufficient financial resources was shown to have a negative effect on entering parenthood for our interviewees.

Regarding partnership status, various studies indicated a much higher proportion of childlessness among women without co-residential relationships than among women who live in cohabitation or marriage. Our qualitative data also showed that the lack of a lasting partner relationship often means that the tem- 
porarily childless will remain childless and even if they want to have children, they cannot realize those desires.

Concerning religiosity and traditional attitudes towards family life, previous empirical studies partly found evidence for the role of value changes in the increasing rate of childlessness: 'family values' seemed to be more important for people having children than for the intentionally childless - but this difference disappeared when the value preferences of people having children and those of the temporarily childless were compared Keizer (2010). In the context of value shifts towards increasing individualization and secularization, associated with the second demographic transition (Lesthaeghe, 2014), when traditional family lifestyles are no longer as attractive and/or compelling as they used to be, researchers usually expect that religious people and those who express traditional family attitudes will have a smaller chance to remain childless than their non-religious counterparts. However, in our interviews we found indications (especially amongst the most religious interviewees) that religiosity can also prevent one from becoming a parent if strict normative rules about the inseparability of marriage, procreative sex and parenthood are followed.

In summary, we found that our findings highlighted that childlessness can hardly be traced back to one single reason or decision. Remaining childless is the culmination of a complex process of several interacting factors such as the lack of a partnership, which can contribute to the postponement of childbearing that in turn can lead to reproductive health problems especially over the age of 3540. At the same time it should be emphasized that not having one's 'own' child does not necessarily lead to a 'childfree' lifestyle: our interviewees reported on their active involvement in raising the children of close family members and/or friends.

\section{Assisted reproduction in Europe}

Involuntary childlessness, or infertility, is a condition that affects a sizable number of couples around the world (Mascarenhas et al. 2012). Assisted reproductive technologies (ART) are an important means to address involuntary childlessness. While the exact distinction between voluntary and involuntary childlessness has always been difficult to define, important reasons for childlessness, such as a perceived lack of a suitable partner or problems of balancing word and children, can be considered to be both voluntary and involuntary (Sobotka, 2010). The current trend of fertility postponement in European societies (Mills et al. 2011) has exacerbated the issue of involuntary childlessness by the fact that female fecundity declines strongly at higher ages and the heterogeneity between women in the pace of fecundity loss, make it difficult for individual women to ascertain how long they can postpone childbearing - or, in other words 'how late can you wait?' (Te Velde et al., 2012, Te Velde and Pearson, 2002).

\subsection{Prevalence of ART in Europe}

Globally, Europe has the largest number of ART treatments. In 2005, the most recent year for which global data are available, 56 per cent of ART treatments were in Europe, followed by Asia (23 per cent) and North America (15 per cent) (Zegers-Hochschild et al. 2014). Given that many European countries have been 
characterized as having the 'lowest-low' fertility (Kohler et al. 2002 ), ART is sometimes expected to not only be a means to alleviate the individual sufferings from childlessness, but also as a potential policy lever to raise fertility rates in Europe, thus interest in ART is substantial. Another key aspect of ART in Europe is the stark variation in terms of ART uptake and ART regulations both across countries and over time.

Figure 7 illustrates the vast variation in ART usage in Europe. The Figure reports the number of treatments by the main group of potential ART patients in a country, namely women between the ages of 15 and 45 years. Denmark, Belgium, Iceland, Sweden, and Slovenia are countries where the largest number of ART cycles is initiated. A comparison of these four countries shows that there is substantial heterogeneity at the top of the distribution. ART treatments in Belgium and Denmark are considerably higher than in Iceland, Sweden, and Slovenia. Furthermore, it is striking that the top group is not completely dominated by affluent western European countries, the reasons of which we discuss shortly in relation to nation-specific regulations, cross-border reproductive care, and the commercialization of ART. Next to Slovenia, the Czech Republic, Estonia, and Serbia are also in the upper half of the distribution, well ahead of wealthy nations such as Switzerland, the Netherlands, or Germany. Towards the bottom of the distribution, it is striking that ART in Germany, Austria, or Ireland is just as widespread as in the Ukraine or in Albania.

\subsection{ART regulation in Europe}

In terms of the legal regulation of ART, Europe is the only continent where legal regulation of ART is widespread. Other major countries where ART is not uncommon, such as India, Japan, and the US, rely largely on voluntary guidelines. While ART regulation is sometimes portrayed as a novel phenomenon, the general notion of governments interfering with the reproductive realm has important historical precedents, for instance when looking at regulations pertaining to marriage and divorce, contraception, births out of wedlock, adoption, and abortion (Spar, 2005).

There are three major ways of regulating the practice of and the access to ART. First, ART can be regulated via guidelines that are sets of rules to be voluntarily followed by practitioners. These guidelines are generally proposed by professional organizations (e.g. obstetrics and gynecology societies). Second, as an alternative or a supplement to guidelines, ART is also often subject to governmental legislation, which are sets of rules codified by law, and that come with penalties for violation. A third route that regulates access to ART is insurance coverage, which given the high costs of infertility treatments can be seen as an indirect regulation of access to ART. Infertility is nowadays seen as a condition leading to disability (WHO and World Bank, 2011) and as such should give infertile individuals a right to treatment.

In terms of findings, there is a trend to regulate ART more strongly across countries. Virtually all countries studied in this project moved from no regulation or guidelines, a less stringent form of regulation, to a more stringent form of legislation, either guidelines or legislation in the period from 1997 to 2012. Access to ART was often regulated by social requirements, which ban certain groups such as unmarried couples, single women and lesbians, from receiving ART treatment. Surprisingly, many countries have no partnership requirements, 


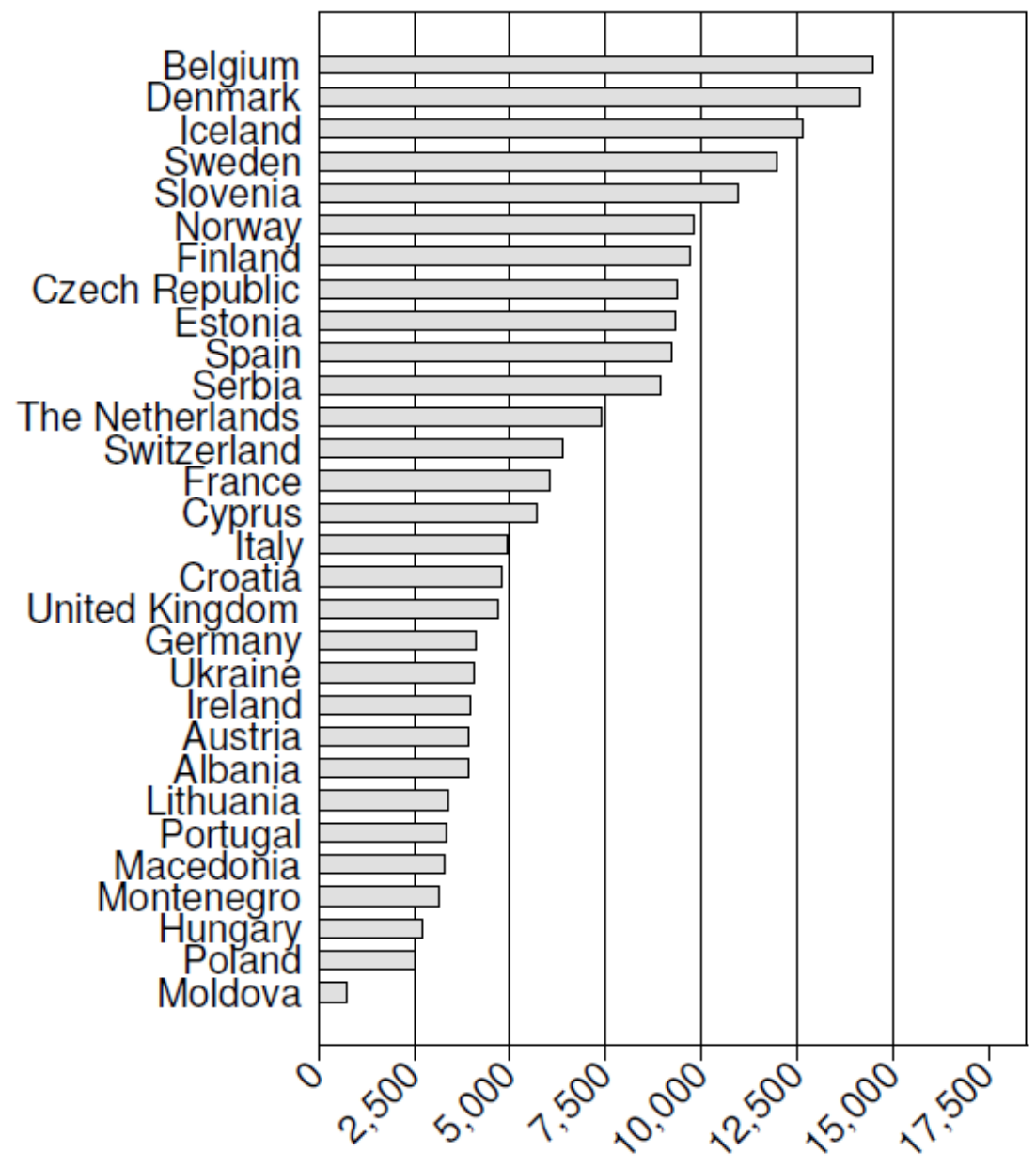

ART cycles per million women age 15-45

Figure 7: ART cycles per million women age 15-45 per country, 2010 Sources: Ferraretti et al. $(2012,2013)$ and Kupka et al. (2014).

Notes: Values for Albania, Estonia, Ireland, Lithuania, Poland, Spain, Serbia, Switzerland, and Ukraine refer to 2008; for Croatia, Cyprus, and France, and Denmark to 2009. 
whereas others require women aspiring treatment to be in a stable relationship. Only a minority of countries demands women to be married, and between 1997 and 2012, a number of countries liberalized their partnership requirements. Single and lesbian women are often banned from treatment. Furthermore, access to specific ART techniques varies across countries. While most countries allow sperm and egg donation, embryo donation is not available in many countries. IVF surrogacy is banned in many places, egg cryopreservation is however, available in all countries we studied. Sex selection and posthumous insemination are only available in a limited number of countries.

\subsection{Consequences of assisted reproduction}

ART is not an effective policy measure to counter low fertility, but usage has grown over time and varies across nations largely in line with differences in affordability and norms and values. Our estimates show that the impact of ART on fertility rates is negligible and that improving access to ART will not affect fertility rates to a meaningful extent. Nonetheless, there is large crosscountry variation in ART usage, which appears to be linked to affordability of treatments on the one hand and to the attitudes towards ART on the other.

The dramatic increase in twinning rates is largely due to ART and not birth postponement. Our analyses reveal that there has been a massive increase in twinning rates across countries; in some instances they have doubled over the course of less than three decades. We are able to show that this is largely attributed to the proliferation of ART treatments, which is one potential driver of increasing twinning rates, and not because of delayed childbearing, which could have been another driver of an increase in the number of twins.

ART pregnancies and deliveries can be more problematic, as our analyses of Italian data show that ART users were older than those who conceived naturally and that ART usage was associated with higher-risk pregnancies and deliveries, which in turn was often explained by twin or triplet births, which are more risky.

\section{Policy recommendations}

\subsection{Childlessness}

Our study shows that childlessness in contemporary Europe should no longer be associated with the stereotypical image of a highly-educated and career-oriented woman. The situation that emerges is much more complex and differentiated across Europe, where childlessness is increasing situated among the less educated strata of society. Neither is childlessness in any clear way associated with women's higher education or the proportion of women in the labor market, as is often assumed at macro level.

The very low rates of voluntary or intended childlessness suggest, and the absence of a substantial increase in wanted childlessness over the last decades, indicates that childlessness in young adults in their late 30's or early 40's is to a large extent unwanted and that voluntary childlessness remains rare even in low fertility contexts. However, in some countries (e.g. Finland, or in the German-speaking countries) we find a considerable group of childless men and 
women in their thirties stating that they do not intend to have children in the future.

Educational differences in childlessness rates further indicate that unwanted childlessness may now be concentrated among those who lack socioeconomic resources, but also among those who can experience a "problematic" life course in terms of union histories, or by extremely fragmented job career or partnership trajectory.

Unfortunately, at the individual level, different aspects of individuals' life generally hypothesized to be linked to childlessness (like secularization, values, occupation, early life course variables) have not been taken into account, because of the lack of comparability among the available data sources. The availability of information that allows us to make a distinction between voluntary childlessness and sterility would be useful not only for research purposes, but it would be of paramount importance to design and implement tailor-made policies that can be explicitly targeted to reduce childlessness, when it is not wanted. If a decade ago the dominant idea among scholars was that policies should remove the obstacles that impede couples to have a second child, today in many European country the main challenge is how to allow people to have at least one child when they want to before it is too late.

The diffusion of parenthood postponement does not necessarily imply lifetime childlessness, but it is also important to remember that the early 30's remain the prime time for childbearing among most European women, and a higher proportion of childlessness at that age can be assumed to predict higher overall lifetime childlessness and lower fertility overall in this age group. Fertility tempo policies should be recommended, to contrast the generalized postponement process, therefore. Policymakers need to have up-to-date data to monitor the phenomenon, to understand the main obstacles to the process of family formation (e.g. late access to employment, low entry salary, discriminatory practices against working mothers, job instability, low wages, expensive housing access) and design and implement policies to allow an easier transition to adulthood, thus allowing lower levels of involuntary childlessness.

Tempo policies should be recommended, to contrast the generalized postponement process which is strongly linked to permanent childlessness. This suggestion is reinforced by the results that the association between educational level and childlessness is country-dependent. The macro-level context seems to influence the way that micro-level characteristics determine childlessness. In those countries characterized by active welfare policies for families (e.g. in Finland), women with higher education levels are those who are less likely to remain childless, because policies support them against the opportunity cost of having children, and the value shift make working women more desirable in the marriage (or union formation) market (Goldscheider et al. 2015). Conversely, countries that are unable to implement such policies and still share traditional values in terms of gender role-set, exhibit the highest percentages of highly educated childless women. This result can help policy makers in understanding the importance of policies allowing people (especially women) to reach, already at younger ages, at least the minimum socio-economic conditions needed to form families, and thus, to enhance parenthood. At the same time, policy should help to avoid that maternity and family life is perceived as competitors to women's labor force participation: where work-life balance is possible and easily available, childlessness is relatively low and stable (e.g. in Scandinavia and in France). 
Childlessness is also low but increasing in Eastern Europe, which still have a markedly early entry into partnerships, compared to Western Europe. Efforts should be made to maintain these possibilities also among younger birth cohorts.

Informative policies to increase the knowledge of biological age limits of human fecundity could also be useful to avoid that the younger generations are unaware of the risks associated to a delay of childbearing in the late thirties or even after the age of forty. At the same time it should be made clear that the probability of success of conception by assisted reproduction-often seen as a solution of extreme delayed maternity - is also age-constrained, a topic we turn to now.

\subsection{Assisted Reproduction}

Based on the findings of this research project, we have generated several policy recommendations:

ART is often heralded as a potential policy solution for low fertility. We examined research that predicted the net impact of ART live births, which is the difference between the observed number of births and a hypothetical one achieved in the absence of ART treatments. The net impact is a smaller, but also a more realistic measure of the impact of ART since it takes into account that couples who undergo ART treatment might spontaneously conceive and the unplanned extra multiple births. Under realistic conditions, the net contribution of ART on the overall birth rate ranges from 0.04 to 0.06 , suggesting that the expectation that ART might substantially increase fertility rates is exaggerated. We can therefore conclude that ART treatments are not an effective policy instrument to counter low fertility.

The strongest associations driving cross-national differences in ART success were affordability of treatment and ethical values regarding when an embryo is a human, influencing the number of embryo replacements. Future policy directives that aim to increase access to ART or understand why or why not certain policies may work should not only prioritize affordability and economic aspects, but consider the oft-forgotten normative and cultural values surrounding human embryos.

Although the number of women 40 and older aspiring ART treatment has grown over time, a striking finding of our research is that success rates for this group are markedly lower. With the chance of around ten per cent for a successful birth in some treatments such as IVF, the question remains as to whether women and couples at these advanced ages are aware of the extremely low chances. There is also the group of younger women who postpone to older ages and are seemingly unaware of the very low success rates of conception as they age. Future policy directives should focus on ensuring that this growing group of ART users and postponers above the age of 40 are aware of the limited success rates of ART at advanced ages. Kocourkova et al. (2014) suggest that ART can be a greater driving factor in fertility rates if it is used earlier in women's life rather than later. While this is of course true, one of the most important reasons for the growing demand for ART is the postponement of childbearing, which is a larger policy question.

Although sperm donation (also with IVF) and oocyte donation appear to be widely available in most countries, more explicit policy recommendations need to be formulated regarding the donation of entire embryos. A public debate 
that still particularly needs to take place in many countries is rules regarding IVF surrogacy. Since they are largely prohibited in most countries, this raises the real concern of cross-border care and creates unclear legal situations for parents and their children who engage in IVF surrogacy. Präg and Mills (2017) listed a number of relevant examples: A famous case that demonstrates the legal problems that can arise is that of twins who were born to a gay male British couple, one of whom one was the biological father, with the help of an anonymous egg donor and a Ukrainian surrogate mother. Because of conflicts between British and Ukrainian laws, the British father was not treated as a parent of the twins, and his children were not allowed to enter the United Kingdom. Conversely, the Ukrainian surrogate mother had waived all rights to custody of her biological offspring in a surrogacy agreement, which was, however, only recognized under Ukrainian law, and not under British law. Similar cases have been reported in Germany: for example, babies who were born outside of the country using surrogacy have been denied citizenship, even though the German parents were named on the birth certificate.

There are serious policy implications for parents and their IVF offspring in relation to rules regarding non-anonymous sperm and egg donation. Only a limited number of countries allow this and there are strong arguments both for and against this regulation. On the one hand, gamete donors may wish to remain anonymous, avoid stigmatization, and have no legal or social obligation to their offspring. Parents may also find the idea of a 'third' parent disruptive. On the other hand, the welfare of ART children is a growing concern, since identification of biological parents may aid them in developing their own identity or in relation to the right to know about hereditary diseases.

Acknowledging the existence of cross-border reproductive care is essential for ART regulation in European countries. Cross-border reproductive care is a transnational practice that forces policy makers to think beyond the confines of the nation-state. Even in the fictitious case that all EU member states would be able to agree on a single ART regulation regime, citizens will continue to travel to pursue the treatment they want (or can afford) in non-EU countries. Under these circumstances, banning some forms of ART will become a largely a symbolic endeavor that at the same time will weaken the value of the regulation when it cannot be enforced effectively.

Rather than resorting to largely symbolic and ineffective measures, policy makers should pause before making harmful reductions in the priority of regulation; ensuring that services that are provided are known to be safe and ensuring that best practices are followed. Furthermore, they should acknowledge the existence of all forms of ART in their family legislation, regardless of whether it is legal or not in their jurisdiction. Banning some or all forms of surrogacy in a country does not absolve governments from having provisions in place for families or individuals with children born through surrogacy. Similarly, banning sperm donation will not resolve issues regarding the rights of children born due to sperm donation.

ART regulation should be seen in conjunction with the regulation of all human reproduction in societies. A liberalization of ART regulation or greater financial support for ART patients that results in greater ART usage will have consequences for the demand for child adoption. Related to this is the regulation of abortion, which is an important driver for the supply of children available for adoption (Spar, 2006). Policymakers should be mindful that these fields 
are related and changes in the regulation of one area will likely result in new developments in the other. But also for infertile couples and individuals it is important to have concerted efforts in these policy areas. Adoption is an important alternative to ART for those who are infertile. Mismatches in the service provision for infertile couples or children who are up for adoption can arise, when ART policies are not in line with adoption regulations. One example concerns the well-documented burdens that arise from IVF treatments, which are often taxing for the psychological wellbeing of women undergoing treatment as well as of their partner. These patients might shy away from seeking help for IVF-related depression as they fear that any documented mental health problem might affect their future chances for adopting a child when the ART treatment fails. Unmet health care needs can thus arise if these policy areas are not treated in conjunction and continue to be dealt with in parallel isolation.

Our research suffers from strong limitations in what we are able to conclude, which is due to the lack of data and clarity about ART in Europe. One persistent concern throughout this project was the accuracy and quality of particularly the policy-level data. The IFFS group recruited international experts to provide accurate data. The majority of the policy data, however, still remains based on a single- or sometimes multiple-respondent survey. More ideal data would be the legal analysis and examination of actual legislation and statutes or the published guidelines given to practitioners by surpra- or national organizations and medical bodies. Clinical and regulatory data would also be useful to understand how these guidelines and legislations are put into practice.

Future endeavors should firstly move towards a greater standardization of data collection of ART treatments and their outcomes to improve the knowledge base on individual antecedents and effects of ART. Second, national databases should be developed to collect quantitative information that allows linking across countries, as cross-border reproductive care needs to be registered properly. Third, there should be initiatives to not only monitor cross-border reproductive care in Europe, but also to support caregivers in providing help for patients both undergoing and returning from cross-border fertility care in these often legally diffuse situations.

\section{Impact}

The scientific impact of Work Package 4 research is witnessed by several publications on main sociological and demographical reviews, books and book chapters co-authored by the team members. At the same time, many contributions have been presented in international conferences as PAA or EPC.

Our research on the whole has had considerable media coverage. Many times, the results we published have been disseminated via newspaper and magazine articles, websites, television, and radio broadcasts. The team members themselves participated in radio and TV shows and webinar seminars.

Collaborations have been started with ART registers in several countries, and with Stakeholders of leading associations of ART patients.

The two co-leaders and a team member were invited to participate to a series of seminars titled 'Policy Responses to Low Fertility and Population Aging: An international comparative study,' organized by the Korean Institute for Health and Social Affairs (KIHASA) and the East-West Center (USA). They are asked 
to collaborate on a project to improve understanding of the patterns and causes of fertility decline in various social, economic, cultural, and political settings and to consider the associated policy implications. The project identified lowfertility countries with varying fertility levels and trends, cultural backgrounds, social patterns, and economic conditions. For each country selected, an expert scholar was invited to write a country paper and to participate in a series of workshops for discussions with experts from other countries.

Results of this study are being published by Springer in two volumes. The first, released in 2015, presents an overview of the demographic and policy implications of the two low-fertility scenarios. Next, it explores five countries currently experiencing very low fertility rates: China, Hong Kong, Japan, Singapore, and the Republic of Korea. It then examines three countries that have close to replacement-level fertility: Australia, the Netherlands, and the United States. Each country is featured in a separate chapter written by a demographer with expert knowledge in the area.

A second volume, published by Springer in 2016, includes chapters on Austria and the Czech Republic, Canada, France, Hungary, Italy, Norway, Spain, Taiwan, and the United Kingdom plus two chapters that provide summaries and cross-country comparisons. These two books go beyond the technical to examine the core institutional, policy, and cultural factors that shape fertility levels and patterns.

Also based on this collaborative research project, the East-West Center and the United Nations Population Division held an Expert Group Meeting on Policy Responses to Low Fertility on 2-3 November 2015 at the United Nations Headquarters in New York. The purpose of the expert group meeting was to broaden the discussion by involving a larger group of policymakers, academics, and representatives of selected UN agencies and international organizations. The meeting distilled lessons learned and provided policy guidance for countries that are experiencing low fertility and population aging, and for those that are likely to face these challenges in the not too distant future. The discussion focused on identifying common features across selected countries and areas as well as distinctive cultural, institutional, and policy features that might affect fertility levels, either deliberately or inadvertently. Such features may include flexibility of the labor market, the link between marriage and childbearing, factors that help or hinder parents in balancing work and family obligations and gender equity.

\section{Conclusion}

The spread of childlessness is one of the main challenges for many European countries. In the next thirty years, childlessness will exacerbate the problem of aging populations, at both the macro and the micro level. The imbalance in the age structure will be more evident in those countries where beside low fertility an increased proportion of people will remain permanently childless. At the individual level, older childless men and women will not be able to rely on their offspring network for care and assistance, but also not for company and social contacts. Moreover, it is not clear what the impact of childlessness on life satisfaction at adult and old age will be, and if this condition - if not desired - may have an impact on psychological well-being and health or on couple stability. 
This Work Package drew on the unique data across an unprecedented time period to chart the societal and individual factors that contribute to childlessness. It demonstrated that the 'myth' of the highly-educated and careeroriented childless women in Europe no longer holds. Rather, childlessness is complex and differentiated across Europe and in many cases is increasingly situated in the lower educated and precarious economic groups in society. We also demonstrated that there are many individuals who face involuntary childlessness, whereas in some countries (e.g. Finland, German-speaking), there is a considerable group of the 'childfree.'

The postponement of parenthood suggests that tempo policies would be the most fruitful to pursue. In other words, policies that empower individuals (particularly women) to achieve the minimum economic conditions to start a family will be the most successful in allowing individuals to achieve both their preferred timing but also the number of children they would like to have.

Fertility in postponement in Europe also means that Europe is the world's largest consumer of ART treatments. There is large variation across countries in both the levels of usage but also whether there are guidelines, governmental legislation or insurance coverage for treatments. We examined these factors across Europe and selected countries from 1997 to 2012 and found that access to ART was often also regulated by social requirements, banning or allowing certain groups such as unmarried couples, single women and lesbians. Most countries allowed sperm and egg donation, with the banning of embryo donation, IVF surrogacy, sex selection and posthumous insemination in most countries.

Our studies enabled us to draw several concrete policy recommendations. First, we concluded that ART treatments were not an effective policy instrument to counter low fertility, since they only contributed between 0.04-0.06 to the overall birth rate. Second, policy-makers should consider not only medical safety, affordability and economic factors, but also the normative and cultural values surrounding human embryos, which often shape national norms and subsequent policies. Third, we urge for more programs on ART and fertility awareness. Although the group of women over 40 were the fastest growing group of ART users, they were also the ones with the most limited rates of success. Fourth, there is a serious gap in rules regarding IVF surrogacy, which often takes place across different countries with various parties of different nationalities subject to a variety of laws and little clarity for ART offspring. Fifth, transparency is required over non-anonymous sperm and egg donation, considering not only the rights of the parents or the 'third' parent, but also the rights and needs of ART offspring. Sixth, acknowledging and developing policies for cross-border reproductive care is paramount for ART regulation. Our seventh suggestion is that ART regulation should be not be seen in isolation, but rather tied into policy regarding all human reproduction and family law in societies. Continuing to deal with these different policy realms in isolation means that we risk falling seriously behind fertility events that are already happening.

Our final recommendation is that there needs to be considerably more effort in improving the quality and accuracy of both childless and ART policy-level and usage data across Europe. Here we also call for a greater standardization of data collection of ART treatments and their outcomes beyond the data that is collected and not publicly available from commercial clinics. National databases could also allow cross-border reproductive care to be registered properly and most importantly, support should be provided for patients who return who are 
often in legally diffuse situations.

\section{References}

Abma, Joyce C. and Gladys M. Martinez, 2006. 'Childlessness Among Older Women in the United States. Trends and Profiles.' Journal of Marriage and Family 68(4): 1045-1056. doi: 10.1111/j.1741-3737.2006.00312.x.

Bhrolcháin, Máire Ní, Éva Beaujouan, and Michael Murphy, 2011. 'Sources of Error in Reported Childlessness in a Continuous British Household Survey.' Population Studies 65(3): 305-318. doi: 10.1080/00324728.2011.607901.

CFE, 2015. Cohort Fertility and Education Database. Census Data on Cohort Parity Distribution Data for Different Countries. cfe-database.org. Accessed 7 July 2015.

Fasouliotis, Sozos J. and Joseph G. Schenker, 1999. 'Social Aspects in Assisted Reproduction.' Human Reproduction Update 5(1): 26-39. doi: 10.1093/humupd/5.1.26.

Ferraretti, Anna Pia, Veerle Goossens, Jacques de Mouzon, Siladitya Bhattacharya, José Antonio Castilla, Vladislav Korsak, Markus Kupka, Karl G. Nygren, Anders Nyboe Andersen, and the European IVF-Monitoring Consortium, for the European Society of Human Reproduction and Embryology, 2012. 'Assisted Reproductive Technology in Europe, 2008. Results Generated from European Registers by ESHRE.' Human Reproduction 27(9): 25712584. doi: $10.1093 /$ humrep/des255.

Ferraretti, Anna Pia, Veerle Goossens, Markus Kupka, Siladitya Bhattacharya, Jacques De Mouzon, José Antonio Castilla, Karin Erb, Vladislav Korsak, Anders Nyboe Andersen, and the European IVF-monitoring Consortium, for the European Society of Human Reproduction and Embryology, 2013. 'Assisted Reproductive Technology in Europe, 2009. Results Generated from European Registers by ESHRE.' Human Reproduction 28(9): 2318-2331. doi: 10.1093/humrep/det278.

Goldscheider, Frances, Eva Bernhardt, and Trude Lappegård, 2015. 'The Gender Revolution. A Framework for Understanding Changing Family and Demographic Behavior.' Population and Development Review 41(2): 207-239. doi: $10.1111 / \mathrm{j} .1728-4457.2015 .00045 . \mathrm{x}$.

González, María-José and Teresa Jurado-Guerrero, 2006. 'Remaining Childless in Affluent Economies. A Comparison of France, West Germany, Italy, and Spain, 1994-2001.' European Journal of Population 22(4): 317-352. doi: $10.1007 / \mathrm{s} 10680-006-9000-\mathrm{y}$.

Hakim, Catherine, 2003. 'A New Approach to Explaining Fertility Patterns. Preference Theory.' Population and Development Review 29(3): 349-374. doi: $10.1111 / \mathrm{j} .1728-4457.2003 .00349 . \mathrm{x}$

HFD, 2015. Human Fertility Database. Input Data Tables on Women by Age and Parity (Selected Censuses and Register-Based Data). humanfertility.org. Accessed 13 July 2015. 
Hoem, Jan M., Gerda Neyer, and Gunnar Andersson, 2006. 'Education and Childlessness. The Relationship between Educational Field, Educational Level, and Childlessness among Swedish Women Born in 1955-59.' Demographic Research 14(15): 331-380. doi: 10.4054/DemRes.2006.14.15.

Keizer, Renske, 2010. Remaining Childless. Causes and Consequences from a Life Course Perspective. Utrecht: Utrecht University.

Kocourkova, Jirina, Boris Burcin, and Tomas Kucera, 2014. 'Demographic Relevancy of Increased Use of Assisted Reproduction in European Countries.' Reproductive Health 11(1): 37. doi: 10.1186/1742-4755-11-37.

Kohler, Hans-Peter, Francesco C. Billari, and José Antonio Ortega, 2002. 'The Emergence of Lowest-Low Fertility in Europe During the 1990s.' Population and Development Review 28(4): 641-680. doi: 10.1111/j.17284457.2002.00641.x.

Kupka, Markus S., Anna Pia Ferraretti, Jacques De Mouzon, Karin Erb, Thomas D'Hooghe, José Antonio Castilla, Carlos Calhaz-Jorge, Christian De Geyter, Veerle Goossens, and the European IVF-Monitoring Consortium, for the European Society of Human Reproduction and Embryology, 2014. 'Assisted Reproductive Technology in Europe, 2010. Results Generated from European Registers by ESHRE.' Human Reproduction doi: 10.1093/humrep/deu175

Lesthaeghe, Ron, 2014. 'The Second Demographic Transition. A Concise Overview of Its Development.' Proceedings of the National Academy of Sciences 111(51): 18112-18115. doi: 10.1073/pnas.1420441111.

Mascarenhas, Maya N., Seth R. Flaxman, Ties Boerma, Sheryl Vanderpoel, and Gretchen A. Stevens, 2012. 'National, Regional, and Global Trends in Infertility Prevalence Since 1990. A Systematic Analysis of 277 Health Surveys.' Plos Medicine 9(12): e1001356. doi: 10.1371/journal.pmed.1001356.

Merz, Eva-Maria and Aart C. Liefbroer, 2012. 'The Attitude Toward Voluntary Childlessness in Europe: Cultural and Institutional Explanations.' Journal of Marriage and Family 74(3): 587-600. doi: 10.1111/j.1741-3737.2012.00972.x.

Miettinen, Anneli, 2010. 'Voluntary or Involuntary Childlessness? SocioDemographic Factors and Childlessness Intentions among Childless Finnish Men and Women aged 25-44.' Finnish Yearbook of Population Research 45: $5-24$.

Miettinen, Anneli, Anna Rotkirch, Ivett Szalma, Annalisa Donno, and MariaLetizia Tanturri, 2015. Increasing Childlessness in Europe. Time Trends and Country Differences. Working Paper 33 of 'Families and Societies'.

Mills, Melinda and Hans-Peter Blossfeld, 2005. 'Globalization, Uncertainty, and the Early Life Course. A Theoretical Framework.' In Blossfeld, HansPeter, Erik Klijzing, Melinda Mills, and Karin Kurz, eds., Globalization, Uncertainty, and Youth in Society, pp. 1-23. London: Routledge. doi: 10.4324/9780203003206 
Mills, Melinda, Ronald R. Rindfuss, Peter McDonald, and Egbert te Velde, 2011. 'Why Do People Postpone Parenthood? Reasons and Social Policy Incentives.' Human Reproduction Update 17(6): 848-860. doi: 10.1093/humupd/dmr026.

Mills, Melinda, Maria Letizia Tanturri, Anna Rotkirch, Tomáš Sobotka, Judit Takacs, Anneli Miettinen, Venetia Kantsa, Despina Nasiri, Maja Djundeva, Cristina Faludi, Jornt Mandemakers, and Nicola Barban, 2013. The Changing Role of Children. Assisted Reproduction, Late Fertility, and Childlessness. Deliverable D4.1 of 'Families and Societies'.

Mills, Melinda, Renske Verweij, and Max Erdmann, 2014. Taking Stock of ART. Regulatory and Economic Aspects. Deliverable D4.5 of 'Families and Societies'.

Parr, Nick, 2010. 'Childlessness Among Men in Australia.' Population Research and Policy Review 29(3): 319-338. doi: 10.1007/s11113-009-9142-9.

Portanti, Martina and Simon Whitworth, 2009. 'A Comparison of the Characteristics of Childless Women and Mother in the ONS Longitudinal Study.' Population Trends 136: 10-20. doi: 10.1057/pt.2009.15.

Präg, Patrick and Melinda Mills, 2015. Assisted Reproductive Technologies in Europe. Towards Legal Coherence and Policy Recommendations. Deliverable D4.7 of 'Families and Societies'.

_ 2017. 'Assisted Reproductive Technology in Europe. Usage and Regulation in the Context of Cross-Border Reproductive Care.' In Kreyenfeld, Michaela and Dirk Konietzka, eds., Childlessness in Europe. Contexts, Causes, and Consequences, pp. 289-309. New York: Springer. doi: 10.1007/978-3-31944667-7_14.

Präg, Patrick, Melinda Mills, Maria Letizia Tanturri, Christiaan Monden, and Gilles Pison, 2015. The Demographic Consequences of Assisted Reproductive Technologies. Deliverable D4.6 of 'Families and Societies'.

Rotkirch, Anna, 2007. 'All That She Wants Is A(nother) Baby? Longing for Children as a Fertility Incentive of Growing Importance.' Journal of Evolutionary Psychology 5(1): 89-104. doi: 10.1556/JEP.2007.1010.

Rowland, Donald T., 2007. 'Historical Trends in Childlessness.' Journal of Family Issues 28(10): 1311-1337. doi: 10.1177/0192513x07303823.

Schenker, Joseph G., 2005. 'Assisted Reproduction Practice. Religious Perspectives.' Reproductive Biomedicine Online 10(3): 310-319. doi: 10.1016/S14726483(10)61789-0.

Sobotka, Tomáš, 2010. 'Shifting Parenthood to Advanced Reproductive Ages. Trends, Causes and Consequences.' In Tremmel, Joerg Chet, ed., A Young Generation Under Pressure? The Financial Situation and the "Rush Hour" of the Cohorts 1970-1985 in a Generational Comparison, pp. 129-154. Berlin: Springer. doi: 10.1007/978-3-642-03483-1_7. 
_ 2017. 'Childlessness in Europe. Reconstructing Long-Term Trends among Women Born in 1900-1972.' In Kreyenfeld, Michaela and Dirk Konietzka, eds., Childlessness in Europe. Patterns, Causes, and Contexts, pp. 17-53. New York: Springer. doi: 10.1007/978-3-319-44667-7_2.

Spar, Debora L., 2005. 'Reproductive Tourism and the Regulatory Map.' New England Journal of Medicine 352(6): 531-533. doi: 10.1056/NEJMp048295.

_ 2006. The Baby Business. How Money, Science, and Politics Drive the Commerce of Conception. Boston, MA: Harvard Business School Press.

Szalma, Ivett and Judit Takács, 2015. 'Who Remains Childless? Unrealized Fertility Plans in Hungary.' Czech Sociological Review 51(6): 1047-1076. doi: 10.13060/00380288.2015.51.6.228.

Takács, Judit and Cristina Faludi, 2016. Narratives of Childlessness. A Qualitative Analysis. Deliverable D4.4 of 'Families and Societies'.

Tanturri, Maria Letizia, 2010. Determinants of Childlessness among Men and Women. Do They Differ? Proceeding of the 45th Italian Statistics Society (SIS) Conference, Padua, 16-18 June 2010, CLUEP, Padova.

Tanturri, Maria Letizia and Letizia Mencarini, 2008. 'Childless or Childfree? Paths to Voluntary Childlessness in Italy.' Population and Development Review 34(1): 51-77. doi: 10.1111/j.1728-4457.2008.00205.x

Te Velde, Egbert, Dik Habbema, Henri Leridon, and Marinus Eijkemans, 2012. 'The Effect of Postponement of First Motherhood on Permanent Involuntary Childlessness and Total Fertility Rate in Six European Countries Since the 1970s.' Human Reproduction 27(4): 1179-1183. doi: 10.1093/humrep/der455

Te Velde, Egbert R. and Peter L. Pearson, 2002. 'The Variability of Female Reproductive Ageing.' Human Reproduction Update 8(2): 141-154. doi: 10.1093/humupd/8.2.141

WHO and World Bank, 2011. World Report on Disability. Geneva: WHO.

Zegers-Hochschild, Fernando, Ragaa Mansour, Osamu Ishihara, G. David Adamson, Jacques de Mouzon, Karl G. Nygren, and Elizabeth A. Sullivan, 2014. 'International Committee for Monitoring Assisted Reproductive Technology. World Report on Assisted Reproductive Technology, 2005.' Fertility and Sterility 101(2): 366-378. doi: 10.1016/j.fertnstert.2013.10.005 